\title{
Study of The Influence of Viscosity on The Morphology of Polyethersulfone Hollow Fiber Membranes/Additives
}

\author{
Rafael Agra Dias ${ }^{a}$, Vanessa da Nóbrega Medeiros ${ }^{a *}$ ¿ Bárbara Ianny Arruda Silva \\ Edcleide Maria Araújo ${ }^{a}$, Hélio de Lucena Lira ${ }^{(\circledR)}$ \\ ${ }^{a}$ Universidade Federal de Campina Grande, Av. Aprígio Veloso, 882, Bodocongó, 58429-140, Campina \\ Grande, $P B$, Brasil
}

Received: December 19, 2018; Revised: September 26, 2019; Accepted: October 2, 2019

\begin{abstract}
The aim of this work was to prepare hollow fiber membrane changing the composition of polyethersulfone, polyvinylpyrrolidone (PVP) and clay, through the phase inversion technique, evaluating the influence of these constituents on the viscosity and distinct morphologies. Flat membranes were produced and their contact angles were determined and showed difference when clay was added and/or PVP. For the hollow fiber membranes, the +addition of these constituents, PVP and/or clay in the solution, can change significantly the viscosity and effect the membrane formation. From the scanning electron microscopy (SEM) images, it was identified the influence on morphology with the compositional variation of each additive, with the PVP promoting shorter precipitation time, favoring the formation of pores of the "fingers" type and increasing the presence of macrovoids. The addition of clay favored the formation of spherical pores, reducing the presence of macropores.
\end{abstract}

Keywords: Membranes, hollow fiber, polyethersulfone, clay, phase inversion.

\section{Introduction}

Through morphological aspects, the membranes are being developed and used commercially in order to separate liquid, gas and solids ${ }^{1-5}$. The study of membranes, presents its motivation based on the energy cost, compared to other processes, besides the efficiency of separation ${ }^{6}$.

Among the types of polymeric membranes, there are natural and synthetic membranes, the massive majority is produced in a synthetic way? ${ }^{7}$. Diverse are the factors that affect the properties of the membranes, from solvent, temperature, additives and others ${ }^{8}$. Among the membrane configurations, at least two types can be obtained through phase inversion technique, hollow fiber and flat polymer membranes ${ }^{9}$. Hollow fiber membranes have a cylindrical shape, with a varied diameter, being prepared by an extruded polymeric solution with a non-solvent in the inner diameter, thus occurring a flow of precipitation of the polymer solution ${ }^{10}$. The internal fluid has the function to accelerate the precipitation of the membrane, forming small pores and improving properties such as porosity, hydrophilicity and permeation, besides preventing the collapse of the fiber walls. There is a tendency towards the formation of an external precipitated layer, with or without small pores, due to the time of exposure of the solution to the air. Contact with water generates an immediate precipitation, creating large pores ${ }^{11}$.

Different types of polymers are used for the development of membranes, such as: polysulfone, cellulose acetate, polyetherimide, polyethersulfone, etc. The polyethersulfone (PES), due to its flexibility in morphology, exhibit a range of applications and, presents hardness and high rigidity,

*e-mail: vanismedeiros@gmail.com. owning bulky groups in the polymeric chains. Its character is amorphous, presenting good thermal and dimensional stability $^{12}$. Among some disadvantages of the membranes of polyethersulfone, can be highlighted: low hydrophilicity and permeability what can cause membrane fouling ${ }^{13}$. For this reason, there is another line of study that are the nanocomposite membranes, adding to the polymer matrix clay materials, aiming to improve mechanical properties and reduce $\operatorname{costs}^{14}$.

In order to obtain polymeric nanocomposites with the addition of clay, bentonite is the most widely used clay, with montmorillonite (MMT) being the predominantly clay mineral ${ }^{15,16}$. There are other additives used in the processing of polyethersulfone, including polyvinylpyrrolidone (PVP), used to control viscosity, accelerate the precipitation and form pores ${ }^{15,16}$.

In this way, adding clay and PVP, we change properties such as viscosity, morphology, hydrophilicity, pore size and quantity ${ }^{13,17}$. This shows the interest in evaluating the morphology of hollow fiber membranes by varying the composition and viscosity of the PES solution, being prepared by phase inversion technique.

\section{Materials and Methods}

\subsection{Materials}

The following materials were used for this research: polyethersulfone - PES, commercially known as Veradel ${ }^{\mathbb{B}}$ 3000p, provided by Solvay; N, N-dimethylformamide P.A./ ACS (DMF) Labsynth Produtos para Laboratório LTDA; polyvinylpyrrolidone - PVP, $\left(\mathrm{C}_{6} \mathrm{H}_{9} \mathrm{No}\right) \mathrm{n}$, produced by 
Labsynth Produtos para Laboratório LTDA and a regional clay provided by Bentonit União Nordeste (BUN).

\subsection{Methodology}

\subsubsection{Preparation of the spinning solution}

They were prepared Three different compositions, performing compositional variations between polymer and additives: PES/PVP, PES/clay and PES/clay/PVP.

To obtain PES/PVP, solution with DMF, PVP and PES, under constant mixing at $1200 \mathrm{rpm}$ for 1 hour was prepared. For PES/clay, initially, dispersions with clay and DMF, under mixing, at the speed of $1200 \mathrm{rpm}$, for a period of 1 hour was prepared, then the PES was added also under stirring for more 1 hour.

For PES/clay/PVP, at first, the dispersion between clay and DMF were prepared under stirring at $1200 \mathrm{rpm}$ for 1 hour. Subsequently, PES and PVP were added, under mixing for 1 hour. All solutions remained at rest for 24 hours, to eliminating bubbles.

\subsubsection{Production of hollow fiber membranes}

To obtain the hollow fiber membranes, $400 \mathrm{~g}$ of solution was used, obtaining a continuous flow in the process. Hollow fiber were formed through an extruder, illustrated in Figure 1, with two concentric holes, allowing simultaneous extrusion of the internal liquid and solution, preventing the solution from collapsing. After extrusion, the hollow fiber membranes precipitated in a non-solvent bath and washed in water and remained immersed in water for 24 hours.

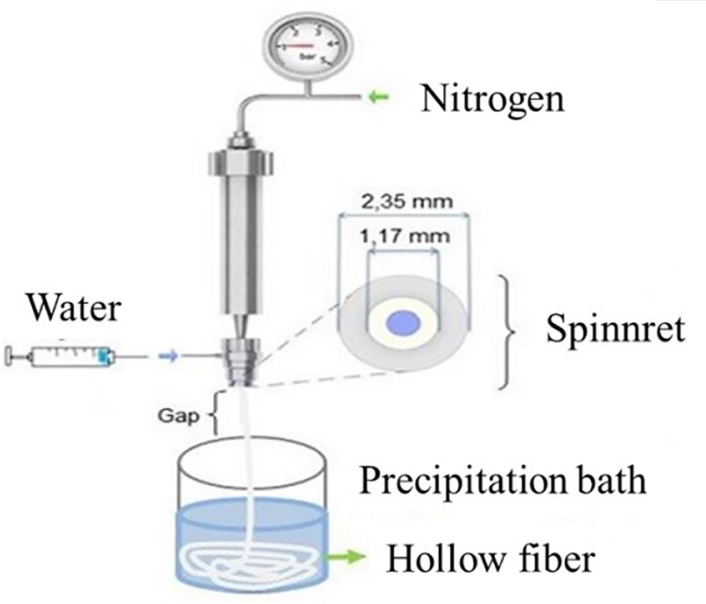

Figure 1. Schematic representation of the extruder and the hollow fiber membranes process ${ }^{18}$.

The parameters for hollow fiber membranes preparation are defined in Table 1 and were obtained through preliminary tests, analyzing the viscosity of the solution, the GAP, the flow of the internal liquid and as well as the flow of the polymeric solution.
Table 1. Experimental parameters for hollow fiber membranes preparation.

\begin{tabular}{lc}
\hline Parameters & Values \\
\hline Solution temperature & $26^{\circ} \mathrm{C}$ \\
GAP & $5 \mathrm{~cm}$ \\
Internal liquid flow & $3 \mathrm{~g} / \mathrm{min}$ \\
Polymer solution flow & $6 \mathrm{~g} / \mathrm{min}$ \\
\hline
\end{tabular}

Flat membranes were produced according to the methodology used by Medeiros ${ }^{20}$, to perform the contact angle test.

\subsection{Characterizations}

\subsubsection{Viscosity measurements}

Viscosity measurements were performed at room temperature, using a rotary viscometer model Q860M21 from Quimis, with reading range from 100 to $600000 \mathrm{mPa}$.s.

\subsubsection{Scanning electron microscopy (SEM)}

For analysis of the morphology of the hollow fiber membranes, cross section images were performed using VEGA 3 - Tescan, operating at $30 \mathrm{kV}$. The samples were fractured in liquid nitrogen and coated with gold.

\subsubsection{Contact angle}

O Contact angle was performed by the sessile drop method, through a portable contact angle meter, Phoenix-I model from Surface Electro Optics - SEO. The drop was formed manually by a micrometric feeder, the drop image was captured by the camera built into the equipment, where subsequently analyzed by software program.

\section{Results and Discussion}

\subsection{Viscosity measurements}

The viscosities of the solutions are listed in Table 2 . With higher polymer concentration and greater viscosity of the solution, the solution did not have sufficient stability to form the hollow fiber, because the precipitation was slow. In solutions with viscosity above $600000 \mathrm{MPa} . \mathrm{s}$, the hollow fiber membrane did not formed, however, flat membranes for contact angle were produced. When adding the PVP, the membrane was formed, even with higher viscosity. This is probably due to the precipitation kinetics that has been modified, shifting the binodal curve of the system.

For the compositions only with clay, only the compositions with 3 and $5 \%$ of clay succeeded to form the membranes, in the other compositions the solutions took longer to precipitate and membranes were not uniform. All compositions with PVP, formed membranes, proving the need for the use of this additive in thermodynamic stabilization of the system. 
Table 2. Composition and viscosity of the solutions

\begin{tabular}{|c|c|c|c|c|c|c|}
\hline Sample & Solvent (wt\%) & PES (wt\%) & PVP (wt\%) & CLAY (wt\%) & Viscosity (mPa.s)* & Membrane \\
\hline AM1 & 70 & 29 & 1 & - & 77581 & Formed \\
\hline AM2 & 70 & 27 & 3 & - & 6674 & Formed \\
\hline AM3 & 70 & 25 & 5 & - & 5899 & Formed \\
\hline AM4 & 70 & 23 & 7 & - & 4583 & Formed \\
\hline AM5 & 70 & 21 & 9 & - & 3658 & Formed \\
\hline AM6 & 70 & 29 & - & 1 & 71092 & Did not formed \\
\hline AM7 & 70 & 27 & - & 3 & 15938 & Formed \\
\hline AM8 & 70 & 25 & - & 5 & 30108 & Formed \\
\hline AM9 & 70 & 23 & - & 7 & 180449 & Did not formed \\
\hline AM10 & 70 & 21 & - & 9 & $* *$ & Did not formed \\
\hline AM11 & 70 & 20 & 9 & 1 & 3274 & Formed \\
\hline AM12 & 70 & 20 & 7 & 3 & 1245 & Formed \\
\hline AM13 & 70 & 20 & 5 & 5 & 2586 & Formed \\
\hline AM14 & 70 & 20 & 3 & 7 & 2833 & Formed \\
\hline AM15 & 70 & 20 & 1 & 9 & 2434 & Formed \\
\hline
\end{tabular}

$* 1 \mathrm{mPa} . \mathrm{s}=1 \mathrm{cP}$

** The equipment was not able to measure, the limit of the viscometer is $600000 \mathrm{mPa} . \mathrm{s}$

As cited by Bouchard et al. ${ }^{21}$, phase inversion involves mixing and precipitation of a three-component system: solvent/polymer/non-solvent. The polymer is first solubilized in a solvent to form a homogeneous solution in a stable thermodynamic state. A change in thermodynamic state is then induced by contact with the polymer solution with a coagulation solution consisting of a non-solvent polymer which is also miscible with the polymeric solvent. This change creates a balance between two phases: a liquid phase poor in polymer and a liquid phase rich in polymer that allows different possibilities of morphology (porous, dense or mixed), which will also depend on a diffusional exchange of solvent and non-solvent and its kinetic separation during membrane formation.

According to $\mathrm{Machado}^{22}$, the increase in the viscosity of the solutions, decreases the mass transfer rates between the fibers and the ambient air, the presence of macromolecular additives (for example, PVP) that moves the binodal curve of the system, favors the increasing of the region where the phase separation process occurs. Thus, the use of PVP makes the solutions more sensitive (more unstable) to the presence of the non-solvent, decreasing the time of precipitation and explaining the decrease of the stability time of the films.

Bildyukevich et al. ${ }^{23}$ explain that the behavior is probably related to changes in the phase separation mechanism. The phase separation diffusion mechanism involves the contact between a polymer solution and an internal (nonsolvent) fluid that leads to concomitant co-counter-diffusion (interdiffusion) of the non-solvent spinning solution. With increased viscosity, mass exchange processes decrease speed. The kinetics delays the precipitation of the polymer exerting a certain effect in both the precipitation rate and the stretch ratio of the spinning of the hollow fiber membrane.

The viscosity influences the precipitation rate and with this the speed of spinning for membranes that use knobs tend to decrease, altering the geometric dimensions of the fibers. On the other hand, in the case of the free-fall spinning process, the precipitation rate is determined not only by the flow of the spinning solution, the flow of the internal liquid and the GAP, but also by the polymer solidification kinetics (increased viscosity) after the separation because of the gravitational under action of its weight ${ }^{23}$.

Another variable that is influenced by viscosity is the shape and quantity of pores. According to Chou and Yang ${ }^{24}$, the pore size increases with the increase of the viscosity of the spinning solution of the hollow fibers membranes, and this tendency can be explained by the increase of the macropores under the action of the delay in precipitation. On the other hand, according to Sukitpaneenit et al. ${ }^{25}$, as the speed of spinning increases, the pore size decreases, and is explained by the increased phase separation rate and shrinkage in high speed of spinning of hollow fiber membranes.

\subsection{Contact angle}

The contact angles of the membranes with distilled water are present in Figure 2. The contact angle for the pure PES membrane (no additives) was approximately $65.3^{\circ 20}$. Membranes with pure PES have a low hydrophilicity, resulting from the presence of the hydrophilic ether groups in PES chains. As noted in the Figures 2(a) and 2(b), the membranes that had in their composition both the PVP and the clay decreased the static contact angle. 

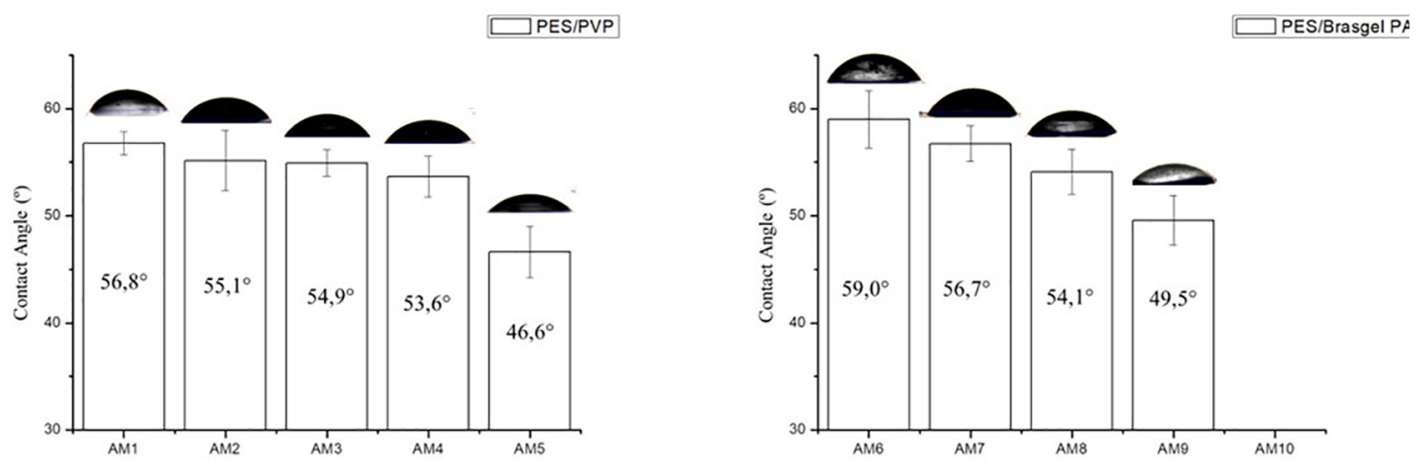

(a)

(b)

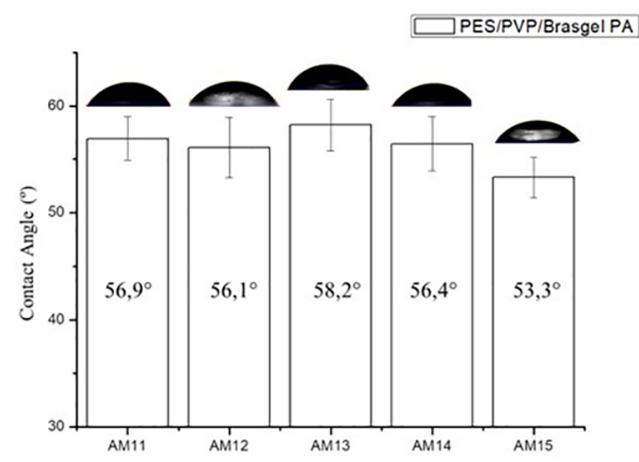

(c)

Figure 2. Contact angles with distilled water for the membranes with: (a) PVP, (b) Clay Brasgel PA and (c) PVP + Brasgel PA.

Both additives had similar behavior, where the higher the concentration of PVP-9\% and Brasgel PA-7\%, the lower the angle $\left(46.6^{\circ}\right.$ and $49.5^{\circ}$, respectively), i.e., the greater the hydrophilicity.

For the compositions that presented the two additives simultaneously (Figure 2c), PVP and Brasgel PA, there is a reduction in the angle, comparing the pure membrane, however among them there are no major changes in values.

The decrease observed in the contact angle reveals that the additives improved the hydrophilicity of the modified PES membranes, the minimum values achieved were for the compositions with $9 \%$ of PVP and 7\% of Brasgel PA.

Similar results for the addition of PVP were obtained by Abdel-Karim et al. ${ }^{[4]}$, where they investigated the use of different polymeric additives with high molar mass, to increase hydrophilicity, and, consequently, water permeability. Another similar result was observed by Al Malek et al. ${ }^{26}$ when studied different concentrations of polyvinylpyrrolidone (PVP) in the preparation of polyethersulfone membrane (PES), using the phase inversion method. They found that adding PVP to the PES solution strongly improves the permeability of the membrane as consequence of increase in the hydrophilicity of the membrane.

For the addition of clay, Mierzwa et al..$^{27}$ achieved reduction of contact angles by adding clay + sodium hexametaphosphate in concentrations of $1 \mathrm{wt} \% ; 2.5 \mathrm{wt} \%$ and $5 \mathrm{wt} \%$. A possible explanation for this effect is because the clay facilitates hydrogen bonds, thus favoring hydrophilicity.

\subsection{Membrane morphology-PVP influence}

The SEM images of the cross sections of the hollow fiber membranes produced by immersion-precipitation technique, with different contents of the PVP are shown in Figure 3. All membranes had the same tendency in their morphology, that is, composed of skins in the internal and external extremities, apparently dense, followed by a double layer of macropores, of the type "fingers". This double layer is due to the precipitations from both sides. According to Pulido et al. ${ }^{29}$, PES membranes produced with the DMF solvent favors this pore type. 

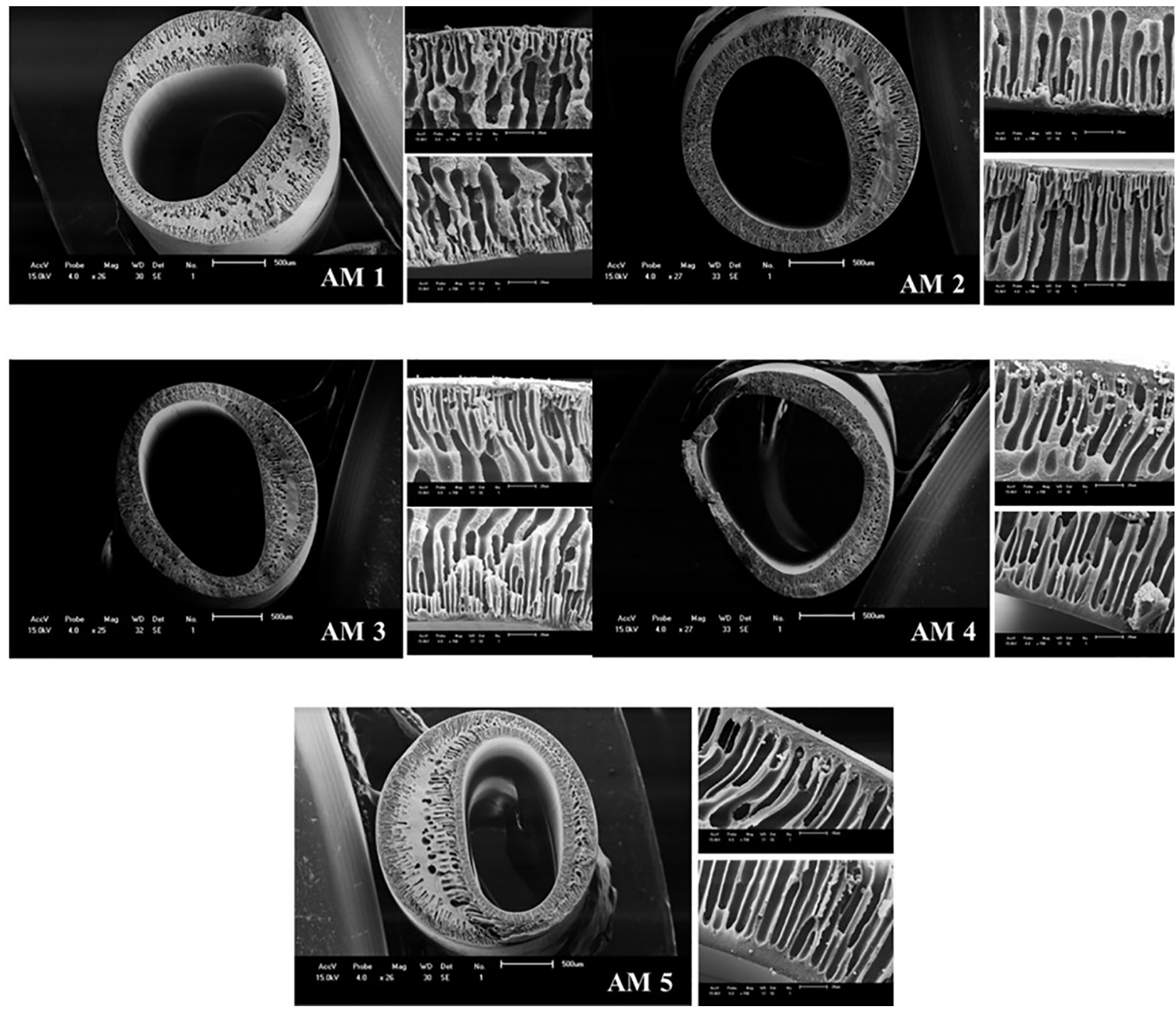

Figure 3. SEM images of PES hollow fiber membranes with PVP concentrations of $1 \mathrm{wt} \%, 3 \mathrm{wt} \%, 5 \mathrm{wt} \%, 7 \mathrm{wt} \%$ and $9 \mathrm{wt} \%$

The increase in the PVP concentration favored the increase of the pore size of "fingers" type, probably due to decreased viscosity, as previously reported. Machado et al..$^{22}$ explains that the instantaneous precipitation in the film/ bath interface, promoted by a high rate of mass transfer in the initial instants of immersion, provides conditions for stabilization of the sublayers, which, in turn, favors the formation of "fingers".

All SEM images show the presence of pores with high interconnectivity. This type of morphology is frequently observed in solutions that contain PVP as a macromolecular additive. As reported by Machado et al. ${ }^{22}$, the phase separation process is due to the nucleation and growth mechanism of the polymer dilute phase, and the interconnectivity induced by PVP would result from the spinodal de-mixing during the membrane formation process. On the other hand, subsequently, Boom et al. 30 admitted that the presence of PVP can promote the separation of phases through the spinodal mechanism, which would give rise to interconnected phases.

According to Guillen et al..$^{28}$, the addition of organic or inorganic components as a third component to a spinning solution is used for to promote or not to a spongy membrane structure, avoiding the formation of macropores in the form of "fingers", improving the interconnectivity of the pores and/or increases hydrophilicity.

Boom et al..$^{30}$ studied the influence of polyvinylpyrrolidone (PVP) as a polymeric additive in the formation of polyethersulfone (PES) membranes. They observed that the addition of PVP suppresses the formation of macrovoids. The polyvinylpyrrolidone can be trapped in the polymeric films and conferring some hydrophilic character. This additive can also release from the membranes after many hours of operation. On the other hand, Yeo et al.$^{31}$ and Mosqueda-Jimenez et al. ${ }^{32}$ concludes that the addition of PVP to the spinning solution of PSf and DMF contributed to the enlargement of the macropores structure in the prepared membranes, rather than the suppression of this structure.

Yoo et al. ${ }^{33}$ suggest that the changes in the viscosity of the solution caused by the addition of PVP change the phase separation rate, which ultimately causes the differences in membrane morphology. Chakrabarty et al. ${ }^{34}$ also studied PVP variation added to the spinning solution. As the molecular 
weight of PVP increased, the membrane sublayers presented dense structures with less macrovoids and the pore number and porosity of the membrane increased. The skin layers of the membrane were thicker as more PVP was added and the number of macrovoids in the form of "finger" gradually disappeared.

Already Abdel-Karim et al. ${ }^{4}$ observed that the modified membrane with PVP presented a greater amount of structure similar to "fingers" than the PES membranes modified by the additives P31R1 (Pluronic) and T904 (Tetronic) due to its hydrophilic character that increases the miscibility of PVP with water. This results in the formation of large macrovoids. Another possible cause is due to the interaction between the amide group in PVP and the PES sulfone group, which may also have caused the formation of macropores in the membrane structure.

\subsection{Morphology of membranes - influence of clay}

The Figure 4 illustrates the SEM images of the cross section of the membranes produced with the addition of the Brasgel PA clay, in the proportions of $3 \mathrm{wt} \%$ and $5 \mathrm{wt} \%$. The other proportions were not possible to produce the membranes, since the viscosities of the spinning solution were quite high, exceeding the limit curve to which the membranes are obtained.

In general, it is possible to observe that all membranes have a typically asymmetric structure with the presence of pores and macropores in the entire cross section. There is an extremely thin and apparently dense upper layer, where they are maintained by porous membrane support, with the presence of pores and macropores. It is also noted that the inclusion of clay favors the formation of spherical pores, with some macropores distributed along the cross section of the membrane.

Spherical pores may be related to precipitation of the membrane with delayed when in contact with the non-solvent bath, since these solutions presented the highest viscosity and confirming the hypothesis of Machado et al. ${ }^{21}$ that explains the instantaneous precipitation in the film/bath interface, promoted by a high rate of mass transfer in the initial instant of immersion, favors the formation of "fingers", already more viscous solutions the effect is the opposite, favoring the spherical pores.

When the proportion of clay increases, the viscosity of the solution is far superior, practically double the value
(Table 2). As an effect of this, there is a greater amount of pores of smaller sizes.

Mierzwa et al. ${ }^{27}$ report that it is possible to identify internal changes of the pore structure due to the addition of clay nanoparticles, where the formation of a thin and spongy structure on the membrane surface is observed. These higher density sponge structures can add resistance to water permeability and act as a filter.

According to Hajasgarkhani et al. ${ }^{35}$, during the formation of the membrane in the coagulation bath, the rate of the precipitation process affects the structure of the prepared membranes. The formation of a more porous structure with greater permeability is favored after the addition of montmorillonite clays (MMT). This may also be related to the increased thermodynamic instability of the polymeric solution. Montmorillonite behaves as a hydrophilic additive with non-solvent properties (an additive that, like other non-solvent, has a strong affinity for the DMF solvent and a weak affinity for the polymer). Thus, MMT increases the thermodynamic instability of the polymeric solution. The intensification of the thermodynamic instability of the spinning solution may favor the formation of a more porous structure.

Mukherjee and $\mathrm{De}^{36}$ observed that with the increase in the concentration of $\mathrm{TiO}_{2}$ nanoparticles, the porous layer spreads through the skin. This type of structure is formed due to the instability of the suspension-coagulation interface, developed during phase inversion.

\subsection{Morphology of membranes-influence of the pair of PVP/clay additives}

The SEM images of the cross section of membranes prepared with the PVP $(9 \mathrm{wt} \%, 7 \mathrm{wt} \%, 5 \mathrm{wt} \%, 3 \mathrm{wt} \%$ and $1 \mathrm{wt} \%$ ) and clay ( $1 \mathrm{wt} \%, 3 \mathrm{wt} \%, 5 \mathrm{wt} \%, 7 \mathrm{wt} \%$ and $9 \mathrm{wt} \%$ ) are visualized in Figure 5. All membranes exhibit a typical asymmetric structure with the presence of macropores. There are two layers in the (outer and inner) edges of the membrane, which are thin and selective, seemingly dense, followed by a porous layer, with macropores and pores "fingers" type, similar to results reported by Salahi et al. ${ }^{37}$ and Mierzwa et al. ${ }^{27}$. This type of morphology is characteristic of membranes, obtained by phase inversion (immersion precipitation), where

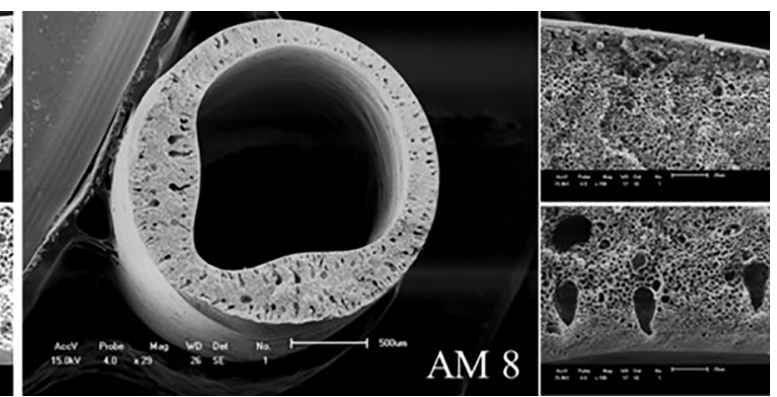

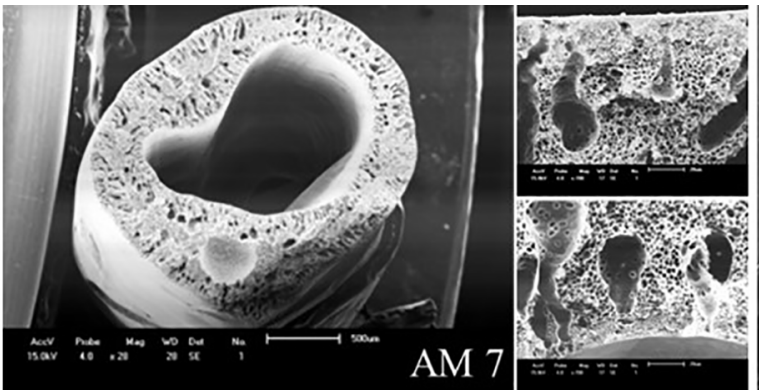

Figure 4. SEM images of PES hollow fiber membranes with Brasgel PA clay ( $3 \mathrm{wt} \%$ and $5 \mathrm{wt} \%$ ). 

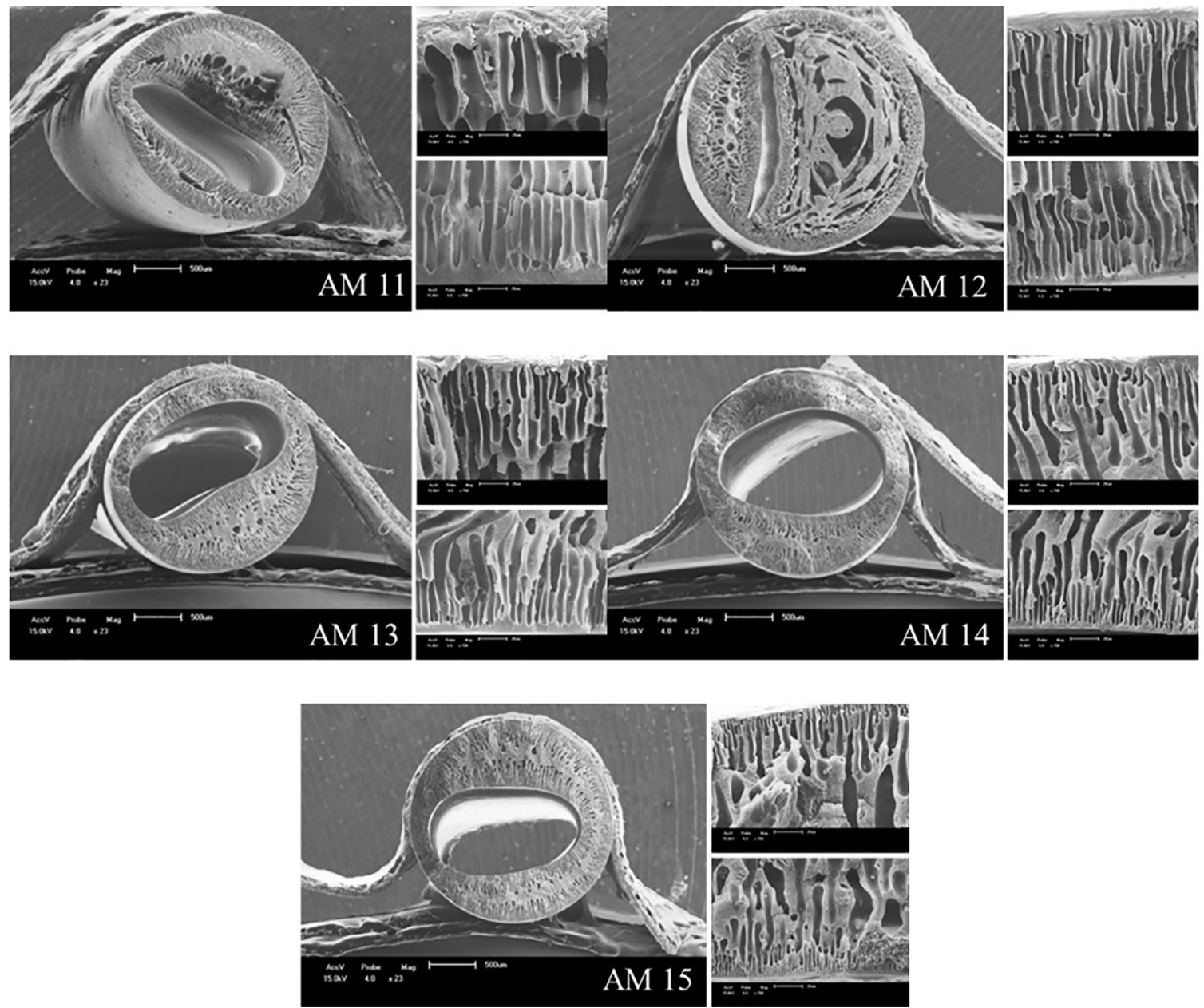

Figure 5. SEM Images of PES hollow fiber membranes with the PVP ( $9 \mathrm{wt} \%, 7 \mathrm{wt} \%, 5 \mathrm{wt} \%, 3 \mathrm{wt} \%$ and $1 \mathrm{wt} \%)$ and clay $(1 \mathrm{wt} \%, 3$ $\mathrm{wt} \%, 5 \mathrm{wt} \%, 7 \mathrm{wt} \%$ and $9 \mathrm{wt} \%)$

the morphology depends on the kinetics of phase inversion and thermodynamics.

The membranes that presented higher PVP contents favored the morphology of the pore type "fingers". When the PVP concentration decreases and increases the clay concentration, this tendency is delayed and "fingers" decrease and spherical pores in the central layer of the membrane appear.

Several mechanisms have been proposed to describe the formation of macropores and pores of "fingers" type. Matz ${ }^{38}$ and Frommer and Lancet ${ }^{39}$ suggested that macrovoids are the result of interfacial hydrodynamic instability controlled by a surface tension gradient. Strathman et al. ${ }^{40}$ believe that it is the precipitation rate that determines the macropore structure. Boom et al. ${ }^{30}$ and Smolders et al. ${ }^{41}$ also showed that the formation of macrovoids occurs in the separation of phases, where nuclei are formed from the diluted phase when the composition of the nucleotides remain stable for a relatively long period of time. The diffusion of the evaporated solvent from the polymer solution causes the growth of these pores. This type of pore is usually formed in systems where instantaneous precipitation occurs, except when the polymer additive concentration and the concentration of non-solvent in the polymer solution exceeds a minimum value $^{30,41}$. Therefore, they affirm that the composition of polymer solution close to the binodal composition favors the formation of spongy structures.

Guillen et al. ${ }^{28}$ explain that the diffusion of the solvent from the polymer solution causes the growth of the macrovoids. Already Chung, Teoh and $\mathrm{Hu}^{42}$ explain that these vacancies and "fingers" pores are probably formed by the spinodal decomposition with the aid of unbalanced localized stresses of the surface tension.

The amount and shape of the pores are fundamental to define and direct the use of the membrane. According to Guillen et al. ${ }^{28}$, the presence of macrovoids in the membranes has advantages and disadvantages. Macropores, for example, may result in membrane compaction or collapse and therefore limit application in high-pressure processes such as reverse osmosis. On the other hand, the macropores structure is 
suitable for ultrafiltration processes and can be used as support layers for composite membranes.

\section{Conclusions}

Hollow fiber membranes were produced with PES and different amount of PVP ( $1 \mathrm{wt} \%, 3 \mathrm{wt} \%, 5 \mathrm{wt} \%, 7 \mathrm{wt} \%$ and $9 \mathrm{wt} \%$ ) and Brasgel PA clay ( $1 \mathrm{wt} \%, 3 \mathrm{wt} \%, 5 \mathrm{wt} \%$, $7 \mathrm{wt} \%$ and $9 \mathrm{wt} \%$ ) and with mixture of PVP/clay. The morphology of the membrane as a function of the viscosity of the spinning solution were evaluated, where the addition of PVP decreased the viscosity of the solution, favoring the high speed of precipitation and the formation of pores of "fingers" type. The clay considerably increased the viscosity of the spinning solution, destabilizing the thermodynamics of precipitation and prevent membrane formation. Membranes with clay and PVP presented spherical and well-defined pores. When PVP and clay was added to the spinning solution, the binodal curve was displaced, favoring the stability and formation of membranes. The morphology of this system was influenced by the amount of PVP, which favored the pores of the type "fingers".

\section{Acknowledgements}

To the Bentonit União Nordeste (BUN), UAEMa/ PPGCEMat/UFCG, MCTI/CNPq, Petrobrás, Finep and $\mathrm{PNPD} / \mathrm{CAPES}$ for financial support.

\section{References}

1. Liao Y, Loh CH, Tian M, Wang R, Fane AG. Progress in electrospun polymeric nanofibrous membranes for water treatment: fabrication, modification and applications. Progress in Polymer Science. 2017;77:69-94.

2. Adewale G, Sudip C, Mavukkandy MO, Arafat HA, Hasan SW. Nanoporous hollow fiber polyethersulfone membranes for the removal of residual contaminants from treated wastewater effluent Functional and molecular implications. Separation and Purification Technology. 2017;189:20-31.

3. Volkov VV, Bildukevich AV, Dibrov GA, Kasperchik VP, Vasilevsky VP, Novitsky EG. Elaboration of composite hollow fiber membranes with selective layer from poly[1-(trimethylsylil)1propyne] for regeneration of aqueous alkanolamine solutions. Petroleum Chemistry. 2013;53(8):619-626.

4. Abdel-Karim A, Gad-Allah TA, El-Kalliny AS, Ahmed SIA, Souaya ER, Badawy MI, et al. Fabrication of modified polyethersulfone membranes for wastewater treatment by submerged membrane bioreactor. Separation and Purification Technology. 2017;175:36-46.

5. Yang Y, Zhang H, Wang P, Zheng Q, Li J. The influence of nanosized $\mathrm{TiO}_{2}$ fillers on the morphologies and properties of PSF UF membrane. Journal of Membrane Science. 2007;288(12):231-238.
6. Bischel HN, Simon GL, Frisby TM, Luthy RG. Management experiences and trends for water reuse implementation in Northern California. Environmental Science and Technology. 2012;46(1):180-188.

7. Smith AL, Stanler LB, Love NG, Skerlos SJ, Raskin L. Perspectives on anaerobic membrane bioreactor treatment of domestic wastewater: a critical review. Bioresource Technology. 2012;122:149-159.

8. Xiao T, Wang P, Yang X, Cai X, Lu J. Fabrication and characterization of novel asymmetric polyvinylidene fluoride (PVDF) membranes by the nonsolvent thermally induced phase separation (NTIPS) method for membrane distillation applications. Journal of Membrane Science. 2015;489:160-174.

9. Carisuelo JP, Gavara R, Hernández-Muñoz P. Diffusion modeling in polymer-clay nanocompósitos for food packaging applications through finite element analysis of TEM images. Journal of Membrane Science. 2015;482:92-102.

10. Arahman N, Arifin B, Mulyaty S, Ohmukai S, Matsuyama H. Structure change of polyethersulfone hollow fiber membrane modified with pluronic F127, polyvinylpyrrolidone, and tetronic 1307. Materials Sciences and Applications. 2012;3(2):72-77.

11. Yang YN, Jun W, Qing-Zhu Z, Xue-Si C, Hui-Xuan Z. The research of rheology and thermodynamics of organic-inorganic hybrid membrane during the membrane formation. Journal of Membrane Science. 2008;311(1-2):200-207.

12. Susanto H, Ulbricht M. Characteristics, performance and stability of polyethersulfone ultrafiltration membranes prepared by phase separation method using different macromolecular additives. Journal of Membrane Science. 2009;327(1-2):125-135.

13. Saranya R, Arthanareeswaran G, Dionysiou DD. Treatment of paper mill effluent using Polyethersulfone/functionalised multi walled carbon nanotubes based nanocomposite membranes. Chemical Engineering Journal. 2014;236(1):369-377.

14. Wang Y, Zhu J, Dong G, Zhang Y, Guo N, Liu J. Sulfonated halloysite nanotubes/polyethersulfone nanocomposite membrane for efficient dye purification. Separation and Purification Technology. 2015;150(1):243-251.

15. Salimi E, Ghaee A, Ismail AF. Improving blood compatibility of polyethersulfone hollow fiber membranes via blending with sulfonated polyether ether ketone. Macromolecular Materials and Engineering. 2016;301(9):1084-1095.

16. Bruggen VB. Chemical modification of polyethersulfone nanofiltration membranes: a review. Journal of Applied Polymer Science. 2009;114(1):630-42.

17. Khulbe KC, Feng C, Matsuura T. The art of surface modification of synthetic polymeric membranes. Journal of Applied Polymer Science. 2010;115(2):855-95.

18. Oliveira SSL, Ferreira RSB, Araujo BA, Medeiros KM, Lucena HL, Araújo EM. Membranas de fibra oca de carbeto de silício: obtenção e caracterização. Revista Eletrônica de Materiais e Processos. 2016;11:164-170.

19. Duarte LT, Pereira CC, Habert AC, Borges CP. Polyurethane/ polyethersulphone composite hollow fibers produced by simultaneous spinning of two polymer solutions. Journal of Membrane Science. 2008;311(1-2):12-22. 
20. Medeiros V, Carvalho TC, Leite AMD, Araújo EM, Lira HL. Polyethersulfone nanocomposite membranes with different montmorillonite clays for oil/water separation. Desalination and Water Treatment. 2019;154:63-71.

21. Bouchard J, Cayla A, Odent S, Lutz V, Devaux E, Campagne C. Processing and characterization of polyethersulfone wetspunnanocomposite fibres containing multiwalled carbon nanotubes. Synthetic Metals. 2016;217:304-313.

22. Machado PST, Habert AC, Borges CP. Membrane formation mechanism based on precipitation kinetics and membrane morphology: at and hollow fiber polysulfone membranes. Journal of Membrane Science. 1999;155(2):171-183.

23. Bildyukevich AV, Plisko TV, Liubimova AS, Volkov VV, Usosky VV. Hydrophilization of polysulfone hollow fiber membranes via addition of polyvinylpyrrolidone to the bore fluid. Journal of Membrane Science. 2017;524:537-549.

24. Chou WL, Yang MC. Effect of take-up speed on physical properties and permeation performance of cellulose acetate hollow fibers. Journal of Membrane Science. 2005;250(1-2):259-267.

25. Sukitpaneenit P, Chung TS. Molecular design of the morphology and pore size of PVDF hollow fiber membranes for ethanolate hollow fibersal polingfouling. Journal of Membrane Science. 2011;374(1-2):67-82

26. Al Malek SA, Seman MNA, Johnson D, Hilal N. Formation and characterization of polyethersulfone membranes using different concentrations of polyvinylpyrrolidone. Desalination. 2012;288:31-39.

27. Mierzwa JC, Arieta V, Verlage M, Carvalho J, Vecitis CD. Effect of clay nanoparticles on the structure and performance of polyethersulfone ultrafiltration membranes. Desalination. 2013;314:147-158.

28. Guillen GR, Pan Y, Li M, Hoek EMV. Preparation and characterization of membranes formed by nonsolvent induced phase separation: a review. Industrial and Engineering Chemistry Research. 2011;50(7):3798-3817.

29. Pulido BA, Waldron C, Zolotukhinb MG, Nunes SP. Porous polymeric membranes with thermal and solvent resistance. Journal of Membrane Science. 2017;539:187-196.

30. Boom RM, Wienk IM, Van Den Boomgaard T, Smolders CA. Microstructures in phase inversion membranes. Part 2. The role of a polymeric additive. Journal of Membrane Science. 1992;73(2-3):277-292.

31. Yeo HT, Lee ST, Han MJ. Role of a polymer additive in casting solution in preparation of phase inversion polysulfone membranes. Journal of Chemical Engineering of Japan. 2000;33(1):180-184.

32. Mosqueda-Jimenez DB, Narbaitz RM, Matsuura T, Chowdhury G, Pleizier G, Santerre JP. Influence of processing conditions on the properties of ultrafiltration membranes. Journal of Membrane Science. 2004;231(1-2):209-224.

33. Yoo SH, Kim JH, Jho JY, Won J, Kang YS. Influence of the addition of PVP on the morphology of asymmetric polyimide phase inversion membranes: effect of PVP molecular weight. Journal of Membrane Science. 2004;236(1-2):203-207.

34. Chakrabarty B, Ghoshal AK, Purkait AK. Preparation, characterization and performance studies of polysulfone membranes using PVP as an additive. Journal of Membrane Science. 2008;315:36-47.

35. Hajasgarkhani MA, Mousavi SM, Saljoughi E. Effects of coagulation-bath temperature and montmorillonite nanoclay content on asymmetric cellulose acetate butyrate membranes. Clays and Clay Minerals. 2013;61(6):541-550.

36. Mukherjee K, De S. Preparation of polysulfone titanium di oxide mixed matrix hollow fiber membrane and elimination of long term fouling by in situ photoexcitation during filtration of phenolic compounds. Chemical Engineering Journal. 2016;302:773-785.

37. Salahi A, Mohammadi T, Behbahani RM, Hemmati M. Asymmetric polyethersulfone ultrafiltration membranes for oily wastewater treatment: synthesis, characterization, ANFIS modeling, and performance. Journal of Environmental Chemical Engineering. 2015;3(1):170-178.

38. Matz R. The structure of cellulose-acetate membranes. 1 . Development of porous structures in anisotropic membranes. Desalination. 1972;10(1):1-15.

39. Frommer MA, Lancet $D$. The mechanism of membrane formation: Membrane structures and their relation to preparation conditions. In: Lonsdale HK, Podall HE, editors. Reverse osmosis membrane research. New York: Plenum Press; 1972.

40. Strathmann H, Kock K, Amar P, Baker RW. The formation mechanism of asymmetric membranes. Desalination. 1975;16(2):179-203.

41. Smolders CA, Reuvers AJ, Boom RM, Wienk IM. Microstructures in phase-inversion membranes. 1. Formation of macrovoids. Journal of Membrane Science. 1992;73(2-3):259-275.

42. Chung TS, Teoh SK, Hu X. Formation of ultrathin highperformance polyethersulfone hollow-fiber membranes. Journal of Membrane Science. 1997;133(2):161-175. 